\title{
Road injuries in school age children: relation to environmental factors amenable to interventions
}

\author{
Rüdiger von Kries, Claudia Kohne, Olaf Böhm, Hubertus von Voss
}

\begin{abstract}
Objectives-To assess the impact of potentially modifiable environmental factors on the risk for pedestrian and cyclist injuries among school age children.

Setting-Population of school age children in Düsseldorf (population 570 000) in the west of Germany. All pedestrian and cyclist injuries involving children between 6 and 14 years brought to the attention of the police between January 1993 and March 1995 were eligible.

Methods-A case-control design was used, with controls matched by age and sex. Criteria for inclusion of cases were: residence in Düsseldorf, and injury within 500 meters from home. A random sample of 174 cases was selected. For each an agesex matched child, resident in Düsseldorf, was randomly selected from a list of all school age children. The environment within a radius of 500 meters around the homes of cases and controls was analysed by blinded on site investigators. These used a standardized questionnaire to assess the number of streets with speed limits of $30 \mathrm{kph}$, the number of pedestrian crossings with traffic lights per street with speed limits of $50 \mathrm{kph}$ or above, and the number of playgrounds for children.
\end{abstract}

Results-Complete information was available for 170 cases and 168 controls. There were significantly more streets with a speed limit of $30 \mathrm{kph}$ around the homes of controls ( $p=0.0003$; mean 9.5 ; $95 \%$ confidence interval (CI) 8.8 to 10.1) than cases (mean $7.8 ; 95 \%$ CI 7.3 to 8.3 ). For every five streets with a speed limit of $30 \mathrm{kph}$ injury risk was reduced by nearly $50 \%$ (odds ratio $0.57 ; 95 \%$ CI 0.43 to 0.76 ). There were also significantly more pedestrian crossings with traffic lights on streets with a speed limit $50 \mathrm{kph}$ or above around the homes of controls $(p=0.0004$; mean 2.7 ; 95\% CI 2.4 to 2.9 ) compared with cases (mean 2.1 ; $95 \%$ CI 1.9 to 2.3 ). Finally there were significantly more playgrounds around the houses of controls $(p=0.04$; mean $1.9 ; 95 \%$ CI 1.7 to 2.2$)$ compared with the houses of cases (mean 1.7; 95\% CI 1.4 to 2.0 ).

Conclusions-Significant associations with injury risk were identified for some prespecified modifiable environmental factors.

(Injury Prevention 1998;4:103-105)

Keywords: environmental risk factors; pedestrians; cyclists; speed limits
Injuries are the main cause of death in children aged $6-14$ years in many western countries. ${ }^{1}$ Most fatal injuries in Germany in this age group are related to traffic, and about two thirds of these deaths are pedestrians or bicyclists. ${ }^{2}$ Developmental, ${ }^{3-5}$ sociodemographic, ${ }^{67}$ and environmental factors ${ }^{8-13}$ contribute to these risks. Developmental and sociodemographic interventions are difficult whereas some environmental factors may be modified more easily.

Environmental factors that may be changed to adapt the traffic environment to the safety of children include reduced speed limits (to 30 $\mathrm{kph}$ ), pedestrian crossings with traffic lights, and playgrounds. These environmental factors have been identified from studies of the locations where traffic accidents occur frequently. ${ }^{59}$ Such studies, however, included numerator data but lack a denominator (the number of children exposed to any specific traffic environment). Therefore these do not allow us to measure the benefit to be attained with modifications of these environmental factors. Consequently much controversy remains as to the efficacy of such interventions.

Case-control studies offer an opportunity to assess the effect of these environmental factors ${ }^{13}$ but, to our knowledge, none focusing on traffic regulation in Europe have been published.

\section{Methods}

A case-control study, with matching on date of birth and sex, was performed to assess the effect of environmental factors on the risk for pedestrian or cyclist injuries in children in Düsseldorf (population 570 000). Police officers in Düsseldorf are required to fill out a structured questionnaire for all injury accidents to which they are called. Such injuries may occur in any public street including parking lots, alleys, and driveways. The questionnaire contains information-for example on the date, time of the day, location, type and time sequence of the accident, a police judgment as to who had caused the accident, vehicles involved, a coded address and age of the injured child, severity of the injury (lethal, severe, for example requiring overnight in hospital treatment, or mild, for example outpatient or no medical treatment). Altogether 481 traffic injuries involving children aged 6-14 as pedestrians or cyclists from January 1993 to March 1995 were considered for this study. Criteria for inclusion were: residence within the boundaries of the municipality, and injury within a radius of 500 meters from the home. A total of 278 children fulfilled these inclusion criteria. Funding only allowed analysis of the
München, Germany

(e-mail: R.vonKries

(a) Irz.uni-muenchen.de.) 
Table 1 Injury risk by number of streets with a speed limit of $30 \mathrm{kph}$

\begin{tabular}{lll}
\hline No of streets & Odds ratio & $95 \%$ CI \\
\hline $0-5$ & 5.3 & 1.6 to 17.6 \\
$6-10$ & 4.3 & 1.4 to 13.4 \\
$11-15$ & 2.5 & 0.8 to 8.1 \\
$>15$ & 1.0 & - \\
\hline
\end{tabular}

*Calculations with "conditional logistic regression" (SAS PROC PHREG) with matching variable age and sex (170 cases and 168 controls). Baseline category: number of streets with speed limit at $30 \mathrm{kph}>15$.

environment of 174 cases and their controls. A random sample of 174 was, therefore, drawn for the study.

For each case, a control child, resident in Düsseldorf, matched by age and sex, was recruited from a complete list of all school age children.

For data protection reasons, the offices gave home addresses of cases and controls only within a range of five consecutive house numbers (the true house number of the individual child could be any of these five numbers). Within a radius of 500 meters around the median of these five houses numbers, environmental factors associated with road safety were assessed. All streets in this area were identified from maps. Information about the characteristics of these streets and their environment was obtained by trained students, who recorded each of these systematically, while not aware of the case or control status of the child living in the respective area.

The characteristics for each street were assessed following a standardised, pretested questionnaire: speed limit of $30 \mathrm{kph}$, as indicated by traffic signs on individual streets; number of pelican crossings (pedestrian crossings with traffic lights) per street with a speed limit of $50 \mathrm{kph}$ or above; and number of playgrounds in the area.

Descriptive statistics and comparisons of cases and controls, using the likelihood ratio $\chi^{2}$ test or Mann-Whitney U test, were calculated with SPSS release 6.1. Odds ratios were calculated with conditional logistic regression with $\mathrm{m}: \mathrm{n}$ matching on age (years) and sex (with PROC PHREG in SAS release 6.11) for example to assess the risk associated with the number of streets with speed limits with $30 \mathrm{kph}$.

\section{Results}

Altogether 174 cases and their controls were included in this study. Complete information on the home environment (number of streets, speed limits on these streets, number of pelican crossings per street with speed limits of $50 \mathrm{kph}$ or above, number of playgrounds) was available for 170 cases and 168 controls. The mean age of the cases was 10 years and the numbers of lethal, severe, and mild cases were four, 39, and 125 respectively (two missing). The numbers of injuries in pedestrians or cyclists were 90 and 76, respectively (four missing). According to the police reports, in 80 of the accidents $(47 \%)$ the children had some responsibility due to their impulsive behaviour or misconception of the traffic situation, whereas the remainder were judged to be the driver's fault.
SPEED LIMIT $30 \mathrm{KPH}$

In the areas surrounding the homes of the controls there were significantly more streets $(\mathrm{p}=0.0003$; mean $9.5 ; 95 \%$ confidence interval (CI) 8.8 to 10.1 ) with a speed limit of $30 \mathrm{kph}$ than in the respective areas of cases (mean 7.8; $95 \%$ CI 7.3 to 8.3 ). Similarly, the mean proportion of streets with a speed limit at 30 $\mathrm{kph}$ was significantly higher in the neighbourhood of controls $(\mathrm{p}=0.01$; median $76 \%$; quartile range $62.4-88.3$ ) than in the neighbourhood of cases (median $70 \%$; quartile range 58.3-81.3). To assess the risk associated with fewer streets with a speed limit of $30 \mathrm{kph}$, the number of these streets were categorised (five streets/category) and the risk for each category compared with a base category of more than 15 streets (table 1). The injury risk for a child living in an area with only zero to five streets with a speed limit of $30 \mathrm{kph}$ was about five times higher (odds ratio 5.3; 95\% CI 1.6 to 17.6 ) compared with a child living in an area with 15 or more streets with a speed limit of $30 \mathrm{kph}$. The respective risk for children living in an area with six to 10 streets with a speed limit of 30 $\mathrm{kph}$ was about four times higher, and that of a child living in an area with 11 to 15 such streets about 2.5 times higher than that for children living in an area with over 15 streets with a speed limit of $30 \mathrm{kph}$. This may also be expressed as the protective effect per five streets with a speed limit of $30 \mathrm{kph}$ : for every five such streets the injury risk was reduced by nearly $50 \%$ (odds ratio $0.57 ; 95 \%$ CI 0.43 to 0.76 ).

\section{NUMBER OF PELICAN CROSSINGS ON STREETS}

WITH A SPEED LIMIT AT $50 \mathrm{KPH}$ OR ABOVE

The mean number of streets with a speed limit of $50 \mathrm{kph}$ or above was significantly higher in the areas around the homes of the cases ( $p=0.006$; mean $3.0,95 \%$ CI 2.7 to 3.3 ) than in controls (mean 2.5; 95\% CI 2.2.to 2.8). There were, however, significantly more pelican crossings in the areas surrounding the homes of the controls $(\mathrm{p}=0.0004$; mean 2.7; $95 \%$ CI 2.4 to 2.9 ) compared with cases (mean $2.1 ; 95 \%$ CI 1.9 to 2.3 ). All of these pedestrian crossings with traffic lights were on straight streets and were not related to junctions. The smallest risk was observed for children living in areas with four or more pelican crossings on streets with a speed limit of $50 \mathrm{kph}$ or more. The injury risk for children living in areas with zero to two pelican crossings on streets with a speed limit of $50 \mathrm{kph}$ or above was more than two times higher compared with children living in areas with four or more pelican crossings on such streets (table 2).

Table 2 Injury risk by number of pelican crossings on streets with a speed limit of $50 \mathrm{kph}$ or above

\begin{tabular}{lll}
\hline $\begin{array}{l}\text { Mean No of pelican } \\
\text { crossings/street }\end{array}$ & Odds ratio & $95 \%$ CI \\
\hline $0-1$ & 2.3 & 1.2 to 4.5 \\
$>1-2$ & 2.4 & 1.3 to 4.3 \\
$>2-3$ & 1.1 & 0.6 to 1.9 \\
$>3$ & 1.0 & - \\
\hline
\end{tabular}

*Calculations with "conditional logistic regression" (SAS: PROC PHREG) with matching variable age and sex (170 cases and 168 controls). Baseline category: mean number of pelican crossings per street $>3$. 
Table 3 Injury risk by number of playgrounds

\begin{tabular}{lll}
\hline No of playgrounds & Odds ratio & $95 \%$ CI \\
\hline 0 & 1.8 & 0.9 to 3.5 \\
$1-3$ & 1.4 & 0.7 to 2.5 \\
$>3$ & 1.0 & -
\end{tabular}

*Calculations with "conditional logistic regression" (SAS PROC PHREG) with matching variable age and sex (170 cases and 168 controls). Baseline category: number of playgrounds $>3$.

\section{NUMBER OF PLAYGROUNDS}

The mean number of playgrounds near homes of controls was significantly higher $(p=0.04$; Mann-Whitney U test; mean $1.9 ; 95 \%$ CI 1.7 to 2.2) than the number surrounding the homes of cases (mean $1.7 ; 95 \%$ CI 1.4 to 2.0 ). The odds ratio of the risk for less than one playground in the neighbourhood compared with four or more playgrounds was 1.8 (95\% CI 0.90 to 3.50 ; table 3 ).

\section{Discussion}

In this study attempts were made to minimise ascertainment and information bias. The ascertainment of cases during the observation period was checked by comparison with national figures. The number of expected cases for the observation period was 523 for Düsseldorf (national traffic injury figures per 100000 for the 6-14 age group in 1994 multiplied by the number of children at risk), and the number cases reported by the police offices was 481 . The selection of controls was at random from a sampling frame that reflected exactly the population in which the cases occurred. Losses from non-compliance were not relevant because information on environmental factors was collected without direct involvement of cases and controls.

A bias towards unity is possible due to imprecision from two potential sources: the house number was only given as a range of five consecutive house numbers. The exact place of the children's home therefore could not be identified leaving some room for random misclassification of the neighbourhood areas. Three students did the field work, each of whom was thoroughly trained. Nevertheless some misclassification cannot be excluded. As the codes to identify cases and controls were only disclosed after all information had been collected, this can only have resulted in random misclassification.

From our data it appears that increasing the number of streets with a speed limit of $30 \mathrm{kph}$, increasing the density of pelican pedestrian crossings on streets with an allowed speed of 50 $\mathrm{kph}$ or above, and increasing the number playgrounds is likely to be effective in reducing the risk of traffic injuries to school age children. One possible objection to this conclusion is that the children living in areas where the risk of traffic injuries is higher due to few streets with a street limit of $30 \mathrm{kph}$, few pelican crossings, or few playgrounds, are also children from low social class families. Low social class is an established risk factor for traffic injuries. ${ }^{14}$ In this study we could not control for socioeconomic factors because individual access to the children was not possible due to data protection rules in Germany.

Furthermore, the traffic volume could not be measured. It appears possible that neighbourhoods with a high number of streets with speed limits of $30 \mathrm{kph}$ are those with low traffic density, which may account for the lower injury risk for children living in these areas. One of the aims of reducing speed limits is to keep busy, through traffic out of the respective streets. The reduction of traffic volume, therefore, would be in the causal pathway of how the introduction of speed limits of $30 \mathrm{kph}$ reduce the risk.

Another objection involves the exposures analysed. It is not clear which components of the possible interventions are most relevant. For example on a street with a speed limit of 30 $\mathrm{kph}$ drivers almost never have priority at street junctions. Priority must be given to vehicles coming from the right. This alone may cause drivers to drive slowly. For decision making in traffic planning it might be important to disentangle the effects of the speed limit and priority regulations in order to decide whether additional speed limits are needed for specific streets. An extension of this study in close cooperation with experts on traffic planning should be the next step in defining the most important measures needed to make the street environment safer for children.

At least one conclusion may be drawn from these data: there is certainly no justification to reduce the number of streets with speed limits of $30 \mathrm{kph}$, as frequently demanded by the automobile lobby.

This is a project of the "Forschungsverbund Public Health, NRW" supported by the BMFT.

1 Rivara FP. Unintentional injuries. In: Pless IB, ed. The epidemiology of childhood accidents. New York: Oxford University Press, 1994: 369-91.

2 Statistisches Bundesamt. Kinderunfälle im Straßenverkehr 1994. Auszug aus Fachserie 8, Reihe 7 "Verkehrsunfälle 1994". Wiesbaden, 1995.

3 Jackel B. Fahrfehlerschwerpunkte radfahrender Kinder und Jugendlicher. Zeitschr Verkehrssicherheit 1995;41:110-15.

4 Bijur P, Golding J, Haslum M, et al. Behavioral predictors of injury in school-age children. Am f Dis Child 1988;142: injury in $1307-12$.

5 Schlag B, Böcher W. Kinder im Straßenverkehr. Troisdorf: Merkur, 1978: 31-41.

6 Deutsche Straßenliga. Kind und Straße. Ein Beitrag zum Deutsche Straßenliga. Kind und Straße. Ein Beitra
innerörtlichen Verkehr. Köln: Müller, 1979: 18-23.

7 Rivara FP, Barber MB. Demographic analysis of childhood pedestrian injuries. Pediatrics 1985;76:375-81.

8 Henning-Hager U, Matthes U, Versteegen D. Einteilung von Verkehrsräumen nach Sicherheitsrisiken für Kinder. Bericht zum Forschungsprojekt 8733 der Bundesanstalt für Straßenwesen. Bergisch Gladbach: Bundesanstalt für Straßenwessen, 1991: 29-38.

9 Pauen-Höppner U, Höppner M. Eine zellenbezogene Analyse der Verkehrsunfälle in Berlin. Zeitschr Verkehrssicherheit 1984;30:17-26.

10 Vormweg K. Verkehrsunfälle mit Kinder in Hamburg 1984 bis 1987. Zeitschr Verkehrssicherheit 1989;35:138-45.

11 Brilon W, Blanke H. Flächenhafte Verkehrsberuhigung: Ergebnisse der Unfallanalysen in 6 Modellstädten. Zeitschr Ergebnisse der Unfallanalysen in 6 .

12 Chapman AJ, Wade FM, Foot HC, eds. Pedestrian accidents. Chichester: John Wiley, 1982: 237-65.

13 Mueller BA, Rivara FP, Lii S-M, et al. Environmental factors and the risk for childhood pedestrian-motor vehicle collision occurence. Am f Epidemiol 1990;132:550-60.

14 Limbourg M. Kinder im Straßenverkehr. Münster: Gemeinde Unfallversicherungs Verband, 1995: 82-95. 